\title{
Environmental Contamination by Dog Feces in Touristic Areas of Italy: Parasitological Aspects and Zoonotic Hazards
}

\author{
Claudia Tamponi, ${ }^{1}$ Stephane Knoll, ${ }^{1}$ Gabriele Tosciri, ${ }^{1}$ Francesco Salis, ${ }^{1}$ Giorgia Dessi, ${ }^{1}$ Maria Grazia Cappai, ${ }^{2}$ Antonio Varcasia, ${ }^{1 *}$ \\ and Antonio Scala ${ }^{1}$ \\ ${ }^{1}$ Laboratorio di Parassitologia - Ospedale Didattico Veterinario, Dipartimento di Medicina Veterinaria, Università degli Studi di Sassari, Sassari, Italy; \\ ${ }^{2}$ Nutrition Desk - Ospedale Didattico Veterinario, Dipartimento di Medicina Veterinaria, Università degli Studi di Sassari, Sassari, Italy
}

\begin{abstract}
Public spaces are common sites of fecal contamination which is concerning considering the prevalence rates of gastrointestinal pathogens carried by pets. Multiple pet-bound parasite species capable of infecting humans have previously been reported in fecal samples collected from urban areas around the globe, including Italy. In addition, the presence of gastrointestinal parasites has recently been shown in pets from the island of Sardinia, a well-known touristic destination. For these reasons, this study aims to evaluate the level of fecal contamination of two of the most important cities on Sardinia. Furthermore, the presence of endoparasites in fecal samples collected was also investigated to assess the parasitological risks associated with such contamination. A grid approach using a geographical information system was applied, followed by transect counting and sampling. A total of 956 and 220 dog feces with an average feces count of 4.7 and 2.6 per 100 linear meters were found for Sassari and Alghero, respectively. In Sassari 15.6\% (52/333) and in Alghero 6.8\% (6/88) of the samples tested positive for parasitic elements. Hookworms, Strongyloides stercoralis, Toxocara sp., and Trichuris vulpis were among the parasites most identified. This study showed significant urban contamination of both Sassari and Alghero with dog feces and the parasites within them, including potentially zoonotic species. The general public as well as tourists visiting the island should be aware of the risks associated with this and appropriate measures taken.
\end{abstract}

\section{INTRODUCTION}

The number of pet animals in our society is ever increasing and is estimated at around 250 million individuals in Europe, present in 80 million homes. Cats make up most of the kept pets, with 103 million animals, followed by 85 million dogs. $^{1}$ Overall, $27.0 \%$ of all Italian households hold at least one dog, and $18.0 \%$ is home to at least one cat. Furthermore, Italy has the fourth highest number of dogs $(7,002,000)$ and the fifth highest number of cats $(7,300,000)$ in Europe. ${ }^{1}$ Italy is one of the European countries with the highest prevalence of domestic animals relative to the human population ( 55 pets per 100 inhabitants), following only Belgium and the Netherlands. ${ }^{2}$

Given the general increasing number of animals in residential areas, critical aspects for society are implied, including environmental contamination and the possible spread of zoonotic agents. First, accidental stepping on animal feces is a common inconvenience in urban areas. Second, besides the dispersal of potentially pathogenic microorganisms, inadequate pet feces disposal leading to the spread of zoonotic parasites in urban areas has more and more been shown to be a legitimate concern. ${ }^{3-13}$ Overall, public spaces including gardens, streets, roadways, and sidewalks are common sites of animal fecal contamination. Furthermore, public squares, playgrounds, parks, and sandpits may be important sources for pet-borne parasites. $5,6,8,10,13,14$

The vast majority of the endoparasites found in cats and dogs have a direct life cycle where adult parasites typically have an enormous reproductive capacity, producing a vast number of eggs or oocysts. Such parasitic load released through feces of the host represents the most important

\footnotetext{
*Address correspondence to Antonio Varcasia, Laboratorio di Parassitologia - Ospedale Didattico Veterinario, Dipartimento di Medicina Veterinaria, Università degli Studi di Sassari, Via Vienna 2, Sassari 07100,
} Italy. E-mail: varcasia@uniss.it pathway of environmental contamination and a source of new infection. ${ }^{5,10,12}$

Human infection results from accidental ingestion or cutaneous penetration of infectious parasitic life stages, and overall, especially, children are considered to be at high risk. ${ }^{4,8-11}$

On average, $12.5-34.4 \%$ of dogs and $10.1-22.8 \%$ of cats are infected with at least one intestinal parasite species. ${ }^{15} \mathrm{~A}$ broad range of parasite types, represented by a variety of lifecycle stages, can be found in the feces of cats and dogs, many of which capable of causing infections in humans as well. Parasites commonly found in the gastrointestinal tract of these pets include small intestinal roundworms (e.g., Toxocara canis, Toxocara cati, and Toxascaris leonina), protozoa (e.g., Cystoisospora spp., Giardia duodenalis, and Cryptosporidium spp.), hookworms (e.g., Ancylostoma caninum and Uncinaria stenocephala), whipworms (e.g., Trichuris vulpis), tapeworms (e.g., Taenia spp., Echinococcus spp., and Dipylidium caninum), and lungworms (e.g. Aelurostrongylus abstrusus, Angiostrongylus vasorum, Troglostrongylus brevior, and Eucoleus aerophilus). ${ }^{4-6,9-12,16-20}$ In recent years, various studies have been carried out regarding urban contamination with pet feces and the parasitic burden. Overall, this issue seems more relevant in developing countries where parasite control programs are limited, and stray dogs still represent a significant challenge. 10,11,21,22

Sardinia hosts a large number of pets: 542,224 dogs and 2,759 cats. $^{23}$ In addition, this figure increases considerably in summer as tourists often travel to Sardinia with own companion animals. ${ }^{12}$ A recent study investigating the prevalence of endoparasites in client-owned cats and dogs in Sardinia concluded this region of Italy to have a particularly high occurrence thereof compared with other parts of Europe. ${ }^{12}$ During this research, intestinal parasites were found in $34.9 \%$ of dogs and $43.4 \%$ cats, and nematodes as well as protozoa were identified in high amounts. ${ }^{12}$ Furthermore, urban environmental contamination with pet feces and the respective 
parasite burden has been investigated in Sardinia in the past, predominantly because this island is highly endemic for cystic echinococcosis. ${ }^{12,24}$

In general, a large amount of fecal contamination in Italian cities can be considered a social and hygienic problem as well as a hazard to public health. Furthermore, up-to-date information on regional prevalence of parasites is crucial for the effectiveness of control measures and could be useful in raising public awareness. For these reasons, this study aims to evaluate the level of fecal contamination of two of the most important cities on the island of Sardinia, a well-known touristic destination located in the middle of the Mediterranean Sea.

\section{MATERIALS AND METHODS}

Study area and geographical information system (GIS). Data for this research were collected between June 2013 and October 2014 in two cities, Sassari and Alghero, in the northern part of Sardinia. Sardinia, the second largest island in the Mediterranean Sea, is located with Spain to the west and mainland Italy to the east, and lies directly south of the French island of Corsica. The climate on Sardinia is characterized by hot and dry summers with mild and wet winters. ${ }^{25}$ Sassari (40 43'50"16N; 08 $\left.33^{\prime} 6^{\prime \prime} 84 \mathrm{E}\right)$, the second largest city in Sardinia $\left(54,704 \mathrm{~km}^{2}\right)$, holds just less than 130,000 inhabitants, whereas Alghero (40 $33^{\prime} 28^{\prime \prime} 44 \mathrm{~N}$; 08 $\left.{ }^{\circ} 19^{\prime} 19^{\prime \prime} 56 \mathrm{E}\right)$, a touristic coastal town, only holds 44,000. Regardless, Alghero $\left(22,443 \mathrm{~km}^{2}\right)$ attracts a large number of visitors every summer because of its attractive coastline and beaches (in 2018, more than 300,000 tourists visited Alghero). ${ }^{26}$ Data for Sassari were collected between June and October 2013, whereas data for Alghero were collected between July and October 2014.

A grid approach followed by transect counting and sampling was used as reported elsewhere. ${ }^{5}$ A GIS was constructed using city maps obtained from the Sassari and Alghero city hall. To uniformly evaluate the canine fecal contamination throughout the city, a grid representing subareas of $250 \times 250 \mathrm{~m}$ was laid over the maps using the software ArcGis $^{\circledR}$ (Esri, Rome, Italy). In this manner, a total of 172 squares were created, 112 in Sassari and 60 in Alghero, respectively. Within each grid square, a $200-\mathrm{m}$ transect best befitting said subarea was chosen to be examined for the presence of pet feces. In addition, transects were selected in an arbitrary manner so as to avoid private-owned roads. The exact length of each transects was measured using the created GIS. The number of feces over these $200-m$ transects was counted by visual inspection of the road and both sidewalks. In addition, the fact if encountered feces were stepped in or not was noted to assess the discomfort caused to people and the potential risk of tracking fecal residue into people's homes. Geographical information system maps with marked transects were printed and handed out to participating researchers, and counting was carried out on weekdays between 9:00 and 12: $00 \mathrm{Am}$. A total of 172 subareas were investigated during this research, and each subarea was investigated once.

Sampling and laboratory analysis. A systematic collection of fecal samples for coprological examination was conducted. Within each subarea defined by the GIS, one fecal sample was collected for every three observed, as reported elsewhere. ${ }^{27}$ At least one sample was collected for each of the 172 subareas containing fecal contamination. Samples were collected using plastic (polythene) bags and stored at $+4^{\circ} \mathrm{C}$ before analysis. A total of 421 stool samples were acquired (333 in Sassari and 88 in Alghero).

Species-specific (cat versus dog) discrimination of stool samples was carried out following both physiological characteristics (apparently normal stools were collected, according to fecal score) and dog's fecal features. ${ }^{28,29}$

Each collected sample was individually analyzed for the presence of parasitological elements (eggs, oocysts, and larvae). Analysis for this research was conducted within the veterinary parasitology laboratory of the Department of Veterinary Medicine at the University of Sassari (UNISS). Parasitological analysis of stool samples was performed by microscopic coprological examination after centrifugation/ flotation technique with a zinc sulfate $\left(\mathrm{ZnSO}_{4}\right)$ flotation solution (specific gravity: 1.2), as previously described. ${ }^{30}$ Parasitic elements were identified according to the species or genus level. ${ }^{31}$

Data and statistical analysis. Data obtained during this research were recorded on a spreadsheet using the software Microsoft Office Excel ${ }^{\circledR}$ (Microsoft Corp., Redmond, WA) and was subsequently analyzed statistically using Epilnfo v. 6 (Epilnfo, Atlanta, GA) and Minitab v. 17 (Minitab, State College, PA) software. Differences between the percentage values of both cities were compared by applying the Pearson's chisquared test. The Mann-Whitney test was used to test the

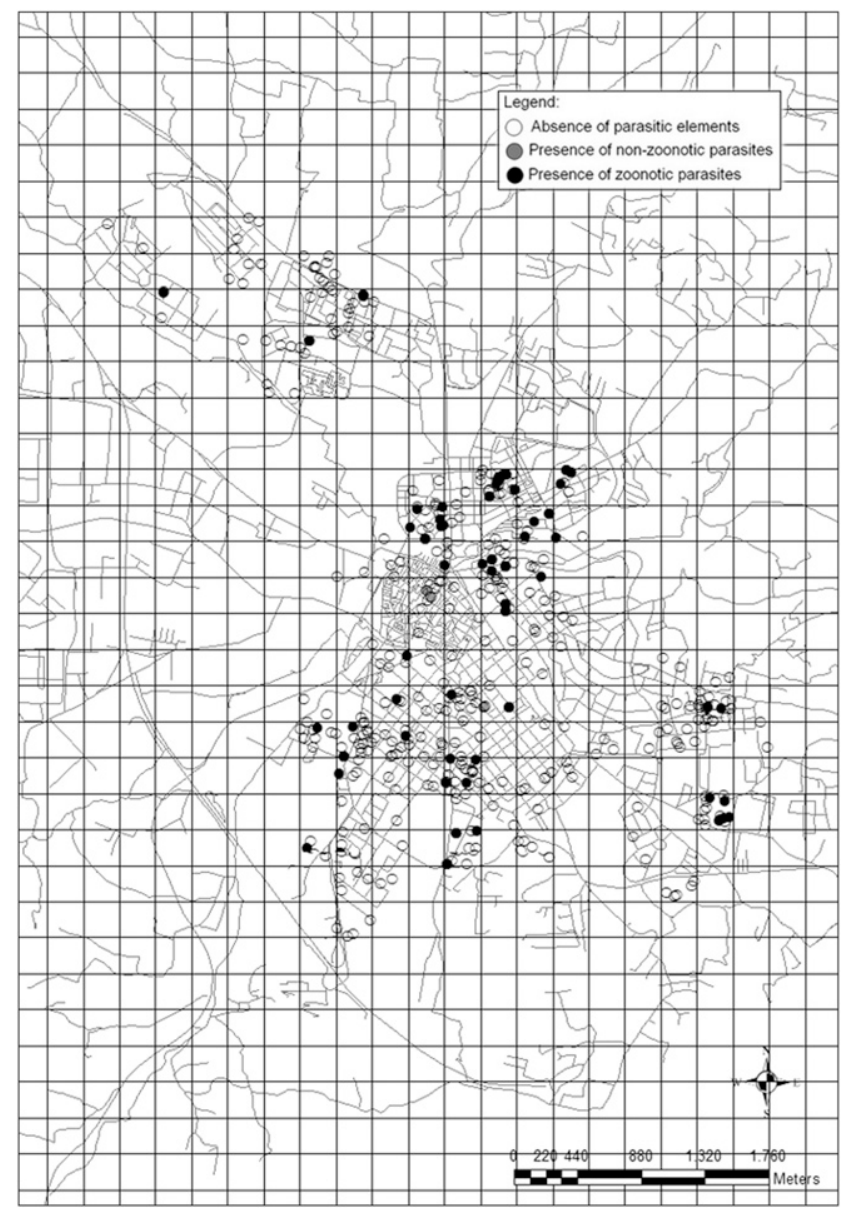

FIGURE 1. Location of negative (white) and positive (black and gray) samples for parasitic elements on the Sassari city map. 
equality of contamination means found in the two cities. The large amount of data collected in Sassari allowed for additional statistical analyses determining possible correlations between fecal contamination and the presence of sensitive areas such as kindergartens and elementary schools, hospitals, and green public areas. At this regard, a Pearson correlation test was performed. All the statistical tests were considered significant for $P<0.05$.

\section{RESULTS}

In both study areas, all samples recovered were of canine origin as judged by their shape and consistency, considering also the site of shed (on ground surface, visible and not covered by sandy or earthy material). In the city of Sassari, $90.2 \%$ of the 112 examined squares contained canine feces (101/ 112). A total of 956 excreta were counted, with a mean intensity of 9.5 feces per square (4.7/100 linear meters). Excrements stepped in by people amounted to $12.2 \%(117 / 956)$ of the total amount of encountered feces.

In total, 333 stool samples were collected in Sassari, and $15.6 \%$ (52/333) tested positive for parasitic elements. The most abundant parasites found in these samples were hookworms (11.1\%), followed by Strongyloides stercoralis (4.8\%), T. canis $(0.9 \%)$ and $T$. vulpis (0.6\%). Next, $0.3 \%$ of tested samples were positive for G. duodenalis, Cystoisospora spp., or Sarcocystis spp. Finally, $0.6 \%$ of samples contained first-stage larvae of lungworms, identified as $A$. abstrusus. None of the tested samples were found to have tapeworm eggs (Figure 1).

Coinfections were found in $3.0 \%$ of examined samples, and one sample $(0.3 \%)$ contained as many as three different parasitic species (T. canis, S. stercoralis, and Sarcocystis spp.). In the city of Alghero, $70.0 \%$ of the 60 examined squares were found to contain pet feces (42/60). A total of 220 excreta were counted (Figure 2), with a mean intensity of 5.2 feces per square (2.6/100 linear meters). Excrements stepped on by people amounted to $1.7 \%(4 / 220)$ of the total amount of encountered feces.

In total, 88 stool samples were collected in Alghero, and $6.8 \%(6 / 88)$ tested positive for parasitic elements. The most abundant parasites found in these samples were hookworms (3.4\%), followed by $T$. canis $(2.3 \%)$ and $T$. vulpis $(2.3 \%)$. In Alghero, only one animal (1.1\%) showed a coinfection with two different species (hookworms and T. canis). Finally, 1.1\% of the samples contained first-stage larvae of $A$. abstrusus. No tapeworm eggs were found in the samples from Alghero.

Statistical analysis showed significantly higher fecal contamination in Sassari than in Alghero $\left(x^{2}=11.35 ; P=0.0007\right)$. A significant difference between the mean contamination of the two cities was found, with a higher value for Sassari $(W=$ $10870.5 ; P=0.0001)$. In addition, the number of feces stepped on by people was also significantly higher in the city of Sassari than in Alghero $\left(x^{2}=8.47 ; P=0.0036\right)$. Overall, parasitic contamination within collected samples was significantly different for both cities $\left(x^{2}=4.54 ; P=0.033\right)$ as well, with the highest value found in Sassari. In regard to each parasite type, only a significant difference in the prevalence rate of hookworms $\left(x^{2}=3.95 ; P=0.0285\right)$ was found between both cities (11.1\% in Sassari versus $3.4 \%$ in Alghero).

The Pearson correlation test showed a statically significant correlation ( $r=0.275 ; P=0.003$ ) between fecal contamination and the presence of green public areas. A significant correlation $(r=0481 ; P<0.001)$ was also found between fecal

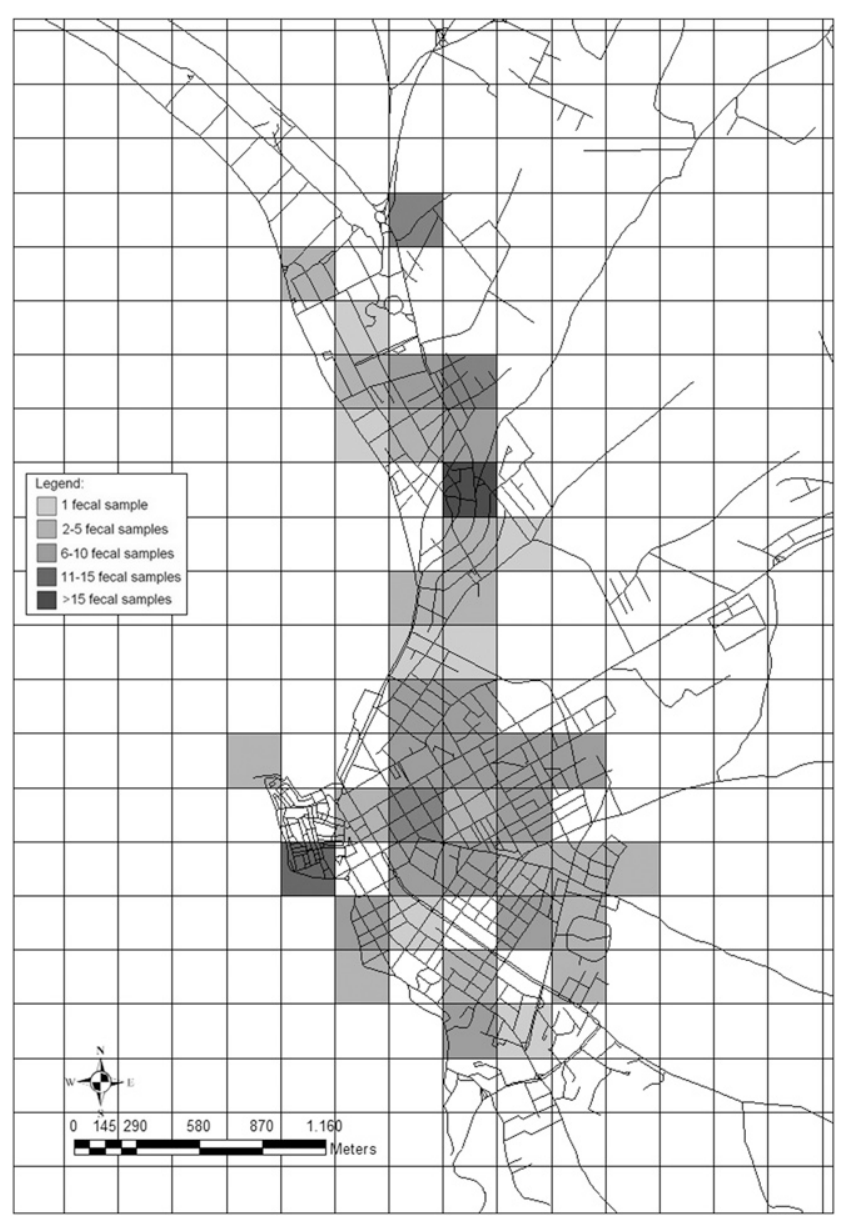

FIGURE 2. Distribution of fecal contamination on the Alghero city map.

contamination and amount of feces stepped on. No significant correlations were found between fecal contamination and the presence of hospitals or schools $(r=-0.162 ; P=0.088)$.

\section{DISCUSSION}

The present study describes a widespread fecal contamination of both monitored areas as canine fecal samples were found in the vast majority of the surveyed subareas. Four nematode species and one protozoa of zoonotic concern (Hookworms, Toxocara spp., S. stercoralis, T. vulpis, and G. duodenalis) were recovered in this study. Furthermore, our data suggest green areas to contribute substantially to environmental fecal contamination, which is in correspondence with previous findings. ${ }^{19}$ Based on the relative amount of feces (percentage of contaminated studied areas), especially Sassari seems to be highly contaminated with pet feces $(90.2 \%)$. Compared with similar studies conducted in the rest of Italy, environmental contamination in Sassari resulted notable. Studies conducted in Messina (57.1\%) and Milan $(86.8 \%)$ all report lower levels of fecal contamination than in Sassari, whereas only a higher level of fecal contamination was found in Naples (98.6\%). ${ }^{5,19,27}$ To the best of our knowledge, only one similar research was recently conducted in Sardinia and was carried out in Alghero. This research reported 7.5 fecal samples for every 100 steps. $^{32}$ As one step 
generally covers a distance of less than $1 \mathrm{~m}$, this figure represents a substantially higher contamination than the one reported here (2.6/100 linear meters) and, thus, is pointing to a general decrease in urban fecal contamination for the region. This decrease is most likely the result of recent implications of strict laws and regulations over the whole of Italy regarding the management of dogs in public settings, putting an obligation on owner to collect the feces of their pets at the risk of penalty. ${ }^{33}$ The percentage of intestinal parasites found in this study seems to be in line with those found in the rest of Italy. Also, the difference between the two cities investigated here (Sassari: $15.6 \%$ and Alghero: $6.8 \%$ ) reflects the variability of the data of other Italian cities (see Table 1), reporting parasitic presence ranging from $1.5 \%$ to $24.1 \%$ of the examined fecal samples. 5,6,19,21,27,34

Previous reports of parasitic presence from pet feces collected from the urban environment of Sardinia on the other hand are much more variable. Two fairly dated studies conducted in Sassari reported a parasitic contamination of $35.0 \%$ and $11.6 \%$, respectively. ${ }^{3,35}$ Given these articles to be several decades old, any conclusions drawn from these are somewhat derivative. In regard to the city of Alghero, a general improvement can be noted. Previous research reported parasitic elements in $20.7 \%$ of excrement from this touristic town, noticeably higher than those found here. ${ }^{32}$ Comparing the urban fecal endoparasite contamination of Sassari and Alghero with those reported in other parts of the world, one can conclude Sardinia to be significantly less plagued by this than both developed and developing countries. Overall, substantial parasitic contamination of urban areas has been recorded in almost every part of the world. In Latin America, parasitological analysis of pet feces collected from public spaces in urban areas showed $37.0 \%$ to $100.0 \%$ of these to be positive for a wide range of intestinal parasites. $8,13,22,36-40$ Similarly, fecal samples collected in Nigeria had a parasite prevalence of $43.3 \%$, and a prevalence of $78.9 \%$ was found in Malaysia. ${ }^{10,41}$ A more recent study reported a prevalence of $19.1 \%$ in stool samples collected in urban streets and farms in Iran. ${ }^{42}$ In regard to developed countries, Mateus found $59.8 \%$ of excrements collected from public areas in Portugal testing positive to gastrointestinal parasites, whereas in Slovakia, a parasitic contamination of $29.9-46.8 \%$ was detected. ${ }^{9,43,44}$ In Turkey, $32.1 \%$ of cat and $28.4 \%$ of dog stool samples collected in an urban setting were found to be contaminated. ${ }^{45}$ Moreover, parks in Spain and Canada were investigated for the presence of intestinal parasites in pet feces, where the latter reported a prevalence of $24.0 \% .{ }^{46,47}$ Intestinal parasites recovered in this research are consistent with the canine parasitic fauna described by previous surveys carried out in Italy. $3,5,6,11,19,21,27,48$

Spurious parasites, namely, the first-stage larvae of $A$. abstrusus, were identified in the samples collected in the present study. These lungworm commonly found in cats neither infect nor cause disease in dogs; their presence in canine feces indicates ingestion of feline feces and testify to a moderate environmental contamination thereof considering that the same areas included in this research have been described as highly endemic for these nematodes in the past. ${ }^{49-51} \mathrm{De}-$ tection of spurious parasites in dog fecal examinations is common and is usually due to coprophagy. ${ }^{52}$ Illustrating this fact, approximately $46.3 \%$ of dog owners surveyed in the Netherlands recognized coprophagic behavior in their dogs. ${ }^{53}$ Regarding cestodes, it is noteworthy that none of the samples examined here scored positive to the presence of tapeworm eggs considering the endemic nature of these parasites to Sardinia. This phenomenon is something already evidenced in other surveys in Sardinia, where taeniid eggs were found only in $0.6 \%$ of dogs and $3.2 \%$ of cats and is probably because of the low detection sensitivity of single copromicroscopic evaluations, resulting from the intermittent presence of proglottids in host fecal matter and the uneven distribution of eggs in feces after proglottid disruption. ${ }^{11,12}$ In addition, overall low presence of canine tapeworms is expected in an urban setting as access of dogs to the viscera of slaughtered or dead animals is much more restricted than in the countryside. ${ }^{24}$

Toxocara canis and hookworms (Ancylostoma spp.) are two well-known zoonotic parasitic agents originating from cats and dogs, which were well represented in the fecal samples recovered from both surveyed municipalities in this research. Although infection usually occurs asymptomatically, if taken up, these parasites can cause visceral and cutaneous larva migrans syndromes in humans, leading to a wide variety of symptoms. ${ }^{54}$ Moreover, ocular larva migrans syndrome can be developed if larvae would to end up in an eye. Infestation with $A$. caninum can furthermore lead to eosinophilic enteritis in people. ${ }^{5,6,8-10,16}$ Hookworm prevalence figures for Sassari $(11.1 \%)$ found in the present survey were slightly higher than those reported $(7.9 \%)$ in the last epidemiological survey carried out in the same study area, whereas, conversely, the

TABLE 1

Parasitic fecal contamination and zoonotic parasites detected in the present study and previous investigations carried out in Italy

\begin{tabular}{|c|c|c|c|}
\hline Reference & City & $\begin{array}{l}\text { Parasitic elements in } \\
\text { examined fecal samples }\end{array}$ & Zoonotic species detected \\
\hline \multirow[t]{2}{*}{ Present study } & Sassari & $15.6 \%$ & $\begin{array}{l}\text { Hookworms }(11.1 \%) \text {, Strongyloides stercoralis }(4.8 \%), \text { T. canis }(0.9 \%) \text {, } \\
\text { T. vulpis }(0.6 \%) \text {, and Giardia duodenalis }(0.3 \%)\end{array}$ \\
\hline & Alghero & $6.8 \%$ & Hookworms $(3.4 \%)$, T. canis (2.3\%), and T. vulpis $(2.3 \%)$. \\
\hline Rinaldi et al. ${ }^{5}$ & Naples & $16.9 \%$ & T. vulpis $(10.1 \%)$, A. caninum $(2.4 \%)$, and $T$. canis $(0.7 \%)$ \\
\hline Risitano et al. ${ }^{27}$ & Messina & $11.5 \%$ & T. canis (3.6\%), hookworms (2.6\%), T. vulpis (1.3\%), and Giardia (6.3\%) \\
\hline Tarsitano et al. ${ }^{6}$ & Bari & $24.1 \%$ & Toxocara spp. $(14.8 \%), A$. caninum $(9.3 \%)$, and $T$. vulpis $(5.5 \%)$ \\
\hline Papini et al. ${ }^{34}$ & Florence & $8.6 \%$ & T. canis $(3.6 \%)$, T. vulpis $(4.6 \%)$, and hookworms $(1.7 \%)$ \\
\hline Zanzani et al. $^{15}$ & Milan & $16.6 \%$ & $\begin{array}{l}\text { T. vulpis (3.7\%), T. canis (1.7\%), Strongyloides spp. (0.9\%), and } \\
\text { hookworms }(0.4 \%)\end{array}$ \\
\hline \multirow[t]{3}{*}{ Traversa et al. ${ }^{21}$} & Rome & $10.5 \%$ & T. vulpis $(7.7 \%), T$. canis $(1.9 \%)$, and $A$. caninum $(1.4 \%)$ \\
\hline & Teramo & $6.6 \%$ & T. vulpis $(5.1 \%)$ and T. canis $(3.6 \%)$ \\
\hline & Padua & $1.5 \%$ & T. vulpis $(1.5 \%)$ and T. canis $(0.7 \%)$ \\
\hline
\end{tabular}

A. caninum = Ancylostoma caninum; $T$. canis $=$ Toxocara canis; $T$. vulpis $=$ Trichuris vulpis. 
prevalence of ascarids found here was lower (0.9\%) than that found in 2017 for the same nematode species (12.1\%). ${ }^{12}$

These differences could be due to the fact that the thus mentioned study, carried out between 2011 and $2015,{ }^{12}$ was carried out on animals who were referred to the Veterinary Teaching Hospital of the UNISS for routine vaccination or clinical visit and included many animals younger than 6 months (with an overall endoparasite prevalence of 47.6). ${ }^{12,54}$

Next, it is worthy to mention the finding of the zoonotic nematode $S$. stercoralis within our samples, a parasite generally recognized to infect stray and shelter dogs in Italy. ${ }^{55,56}$ Whereas infection with this roundworm species causes no harm in healthy individuals, infestation of immunocompromised subjects can even prove fatal as the larval stages of $S$. stercoralis penetrate the gut wall and disseminate to other organs, causing what is known as "disseminated strongyloidiasis." $" 57$ Furthermore, the low percentage reported here could be an understatement of the real occurrence of this zoonosis as the applied diagnostic technique bears a low sensitivity for the detection of this parasite which, in any case, has not been reported in a previous large-scale survey in the same study area. ${ }^{12}$ Instead, the use of the Baermann test or real-time PCR would consist of a more accurate approach. ${ }^{56}$

Finally, G. duodenalis is another endoparasite transferred from pets capable of causing infection and clinical symptoms in humans, although rare in healthy people..$^{5,10-12,30,58}$ In addition, besides being the only zoonotic protozoa found during this research, a lower prevalence was found than previously reported for dogs in Sardinia. ${ }^{12,30}$ In view of this datum, the prevalence in our study was potentially underestimated because the sensitivity of single fecal examinations can be low for the detection of chronic Giardia infections. ${ }^{59}$ Last, Pipia reported a particularly high $(26.3 \%)$ rate, possibly due to the sampling of animals originating from shelters where transmission of Giardia could be higher. ${ }^{30}$ Although no molecular characterization of this parasite was carried out in this survey, the zoonotic potential of Giardia cannot be ignored in relation to the presence of assemblage $A$ and subtype $A 2$, reported in the same area. ${ }^{30}$ The zoonotic potential of other endoparasites typically found in dogs, such as $T$. vulpis, is still unclear even though clinical infections with this particular parasite have been reported, including cases of visceral larva migrans and patent intestinal infections. ${ }^{9,12,60-62}$ Furthermore, T. vulpis is worthy of attention because this parasite is often misdiagnosed because of its similar egg morphology to those of E. aerophilus, for which, contrary to T. vulpis, a zoonotic potential effectively has been proven. ${ }^{63}$

In recent years, the health authority (Azienda Tutela Salute Sardegna) together with each individual municipality, including Sassari and Alghero, have invested significant resources towards making Sardinia more pet-friendly and toward the fight against fecal contamination. Efforts of these organizations include the creation of specific dog beaches, launching of educational campaigns, and the installation of dispensers providing tools for proper fecal disposal in urban and common areas. In addition, these organizations provide a free microchipping service for dogs (see here), finance a free 24-hour veterinary emergency service at the Veterinary Teaching Hospital of Sassari (see here), and are responsible for the management of stray dogs. Even though stray dogs continue to be an actual challenge, this issue is very well managed in the two study areas.
Regardless, contamination of public areas with dog feces is furthermore a social behavioral problem demonstrating poor civic sense. In Italy, a ministerial ordinance (published in Official Gazette of the Italian Republic, August 6, 2013) regulates the public management of dogs: art. 1 paragraph 4 and states: "... It is mandatory for anyone walking a dog in urban areas to collect the feces of said dog and to carry with them suitable instruments for the collection of feces." In addition, within the investigated municipalities, specific municipal regulations have been issued implementing administrative penalties against any citizens failing to comply.

The large amount of excrements stepped on by people (12.2\% of the total amount of encountered feces in Sassari) illustrates the considerable inconvenience urban fecal contamination causes. Besides, feces particles stick to shoes, leading to the dispersal of fecal matter into buildings and homes, representing an infection risk for its inhabitants. This is especially true for wheelchair users and people pushing around a baby carriage, who often cannot avoid them. This last case in particular could represent a significant source of infection for young children as these habitually crawl around the house, coming into contact with anything tracked in through shoes or wheels.

Considering the significant fecal and parasitological contamination identified in Sassari and Alghero during this research and the risks this poses to both animal and public health, advisement of future routine monitoring of this issue is fully warranted. In addition, although an indication of general improvement in regard to urban fecal contamination could be noted here, further awareness campaigns should be organized to adequately inform and orient public knowledge about the risks associated with such contamination and to stimulate pet owners about the need for proper disposal of pet excreta. Likewise, as there is always room for improvement in regard to pet health, informative campaigns regarding proper antiparasitic care for pets are not unfounded. Furthermore, parasitological contamination of Sassari and Alghero does not solely represent hazards to the resident animal and human population as Sardinia is a well-known and frequented tourist destination. A report from the Sardinian government states more than 3,300,000 tourists visited Sardinia in 2018, more than one million of which coming from northern Europe countries (e.g., Germany, France, Switzerland, the Netherlands, and the United Kingdom). ${ }^{64}$ In Addition, as stated before, tourists often travel to Sardinia with their pets which subsequently are at risk of infection, possibly with species not occurring in their native country. ${ }^{12,65,66}$ Besides, high parasitic load in the environment not only poses a direct health risk to visitors, but the high mobility on and off the island also increases the probability of transmission of parasites overseas. ${ }^{67}$ For these reasons, owners should be advised to apply appropriate antiparasitological measures for their pets when traveling to endemic areas like Sardinia, both to avoid diffusion of outer species into the island and getting infected in turn with resident parasites. ${ }^{67,68}$

Finally, besides being a health hazard, one can state urban fecal contamination to be an undesirable condition in any touristic destination and overall improvement of the situation to have feasible consequences for the image of Sardinia and Italy.

Received March 5, 2020. Accepted for publication May 4, 2020. 
Published online June 29, 2020.

Financial support: This study was funded within the project "La fecalizzazione ambientale degli animali da compagnia e gli insetti vettori come fattori di rischio zoonosi in aree urbane e suburbane" (CRP 26627) by Legge Regionale 7, 2012; Regione Autonoma della Sardegna, Italy.

Authors' addresses: Claudia Tamponi, Stephane Knoll, Gabriele Tosciri, Francesco Salis, Giorgia Dessi, Antonio Varcasia, and Antonio Scala, Laboratorio di Parassitologia - Ospedale Didattico Veterinario, Dipartimento di Medicina Veterinaria, Università degli Studi di Sassari, Sassari, Italy, E-mails: claudiatamponi@yahoo.it, stephane_knoll@ hotmail.com, gtosciri@yahoo.com, frsalis@uniss.it, giorgia.dessi87@ tiscali.it, varcasia@uniss.it, and scala@uniss.it. Maria Grazia Cappai, Nutrition Desk - Ospedale Didattico Veterinario, Dipartimento di Medicina Veterinaria, Università degli Studi di Sassari, Sassari, Italy, E-mail: mgcappai@uniss.it.

\section{REFERENCES}

1. FEDIAF, European Pet Food Industry Federation, 2018. European Statistics. Facts and Figures. Available at: http://www.fediaf.org/ images/FEDIAF_Facts_and_Figures_2018_ONLINE_final.pdf. Accessed January 1, 2020.

2. FVE, Federation of Veterinarians of Europe, 2019. VETSURVEY, Survey of the Veterinary Profession in Europe 2018-2019. Available at: https://www.fve.org/cms/wp-content/uploads/ FVE_Survey_2018_WEB.pdf. Accessed January 1, 2020.

3. Poglayen $G$ et al., 2000. Canine zoonoses by environmental faecalization. Parassitologia 42: 220-222.

4. Lia R, La Montanara C, Leone N, Pantone N, Llazari A, Puccini V, 2002. Canine helminthic fauna and environmental faecalization in the town of Bari (Apulia region, southern Italy). Parassitologia 44: 92.

5. Rinaldi L, Biggeri A, Carbone S, Musella V, Catelan D, Veneziano V, Cringoli G, 2006. Canine faecal contamination and parasitic risk in the city of Naples (southern Italy). BMC Vet Res 2: 29.

6. Tarsitano E, Greco G, Decaro N, Nicassio F, Lucente MS, Buonavoglia C, Tempesta M, 2010. Environmental monitoring and analysis of faecal contamination in an urban setting in the city of Bari (Apulia region, Italy): health and hygiene implications. Int J Environ Res Public Health 7: 3972-3986.

7. Cinquepalmi V, Monno R, Fumarola L, Ventrella G, Calia C, Greco MF, de Vito D, Soleo L, 2013. Environmental contamination by dog's faeces: a public health problem? Int J Environ Res Public Health 10: 72-84.

8. Ribeiro LM, Dracz RM, Mozzer LR, Lima WDS 2013. Soil contamination in public squares in Belo Horizonte, Minas Gerais, by canine parasites in different developmental stages. Rev Inst Med Trop 55: 229-231.

9. Mateus TL, Castro A, Ribeiro JN, Vieira-Pinto M, 2014. Multiple zoonotic parasites identified in dog feces collected in Ponte de Lima, Portugal-a potential threat to human health. Int J Environ Res Public Health 11: 9050-9067.

10. Ayinmode AB, Obebe OO, Olayemi E, 2016. Prevalence of potentially zoonotic gastrointestinal parasites in canine faeces in Ibadan, Nigeria. Ghana Med J 50: 201-206.

11. Simonato G, di Regalbono AF, Cassini R, Traversa D, Tessarin C, Di Cesare A, Pietrobelli M, 2017. Molecular detection of Giardia duodenalis and Cryptosporidium spp. in canine faecal samples contaminating public areas in northem Italy. Parasitol Res 116: 3411-3418.

12. Tamponi $C$ et al., 2017. Endoparasites detected in faecal samples from dogs and cats referred for routine clinical visit in Sardinia, Italy. Vet Parasitol Reg Stud Rep 10: 13-17.

13. Rubel D, Nemirovsky SI, Gorosito I, Servián A, Garbossa G 2019. Factors affecting canine fecal and parasitic contamination of public green spaces of Buenos Aires city, Argentina, and visitors' perception of such contamination. J Urban Ecol 5: 1-11.

14. Milkovic M, Carbajo AE, Rubel D, 2009. Spatial distribution of canine faeces in Buenos Aires suburbs: implications for public health. Area 41: 310-318.

15. Zanzani SA, Gazzonis AL, Scarpa P, Berrilli F, Manfredi MT, 2014. Intestinal parasites of owned dogs and cats from metropolitan and micropolitan areas: prevalence, zoonotic risks, and pet owner awareness in northern Italy. Biomed Res Int 2014: 696508.

16. Lee AC, Schantz PM, Kazacos KR, Montgomery SP, Bowman $\mathrm{DD}, 2010$. Epidemiologic and zoonotic aspects of ascarid infections in dogs and cats. Trends Parasitol 26: 155-161.

17. Traversa D, Di Cesare A, Conboy G, 2010. Canine and feline cardiopulmonary parasitic nematodes in Europe: emerging and underestimated. Parasit Vectors 3: 62.

18. Riggio F, Mannella R, Ariti G, Perrucci S, 2013. Intestinal and lung parasites in owned dogs and cats from central Italy. Vet Parasitol 193: 78-84.

19. Zanzani SA, Di Cerbo AR, Gazzonis AL, Genchi M, Rinaldi L, Musella V, Cringoli G, Manfredi MT, 2014. Canine fecal contamination in a metropolitan area (Milan, north-western Italy): prevalence of intestinal parasites and evaluation of health risks. ScientificWorldJournal 2014: 132361.

20. Giannelli A et al., 2017. Lungworms and gastrointestinal parasites of domestic cats: a European perspective. Int J Parasitol 47: 517-528.

21. Traversa D, Frangipane di Regalbono A, Di Cesare A, La Torre F, Drake J, Pietrobelli M, 2014. Environmental contamination by canine geohelminths. Parasit Vectors 7: 67.

22. Cortez-Aguirre GR, Jiménez-Coello M, Gutiérrez-Blanco E, Ortega-Pacheco A, 2018. Stray dog population in a city of southern Mexico and its impact on the contamination of public areas. Vet Med Int 2018: 2381583.

23. Ministero della Salute, 2020. Banca Dati dell'Anagrafe Animali d'Affezione. Available at: http://www.salute.gov.it (consulted on 20/01/2020). Accessed January 1, 2020.

24. Varcasia A, Tanda B, Giobbe M, Solinas C, Pipia AP, Malgor R, Carmona C, Garippa G, Scala A, 2011. Cystic echinococcosis in Sardinia: farmers' knowledge and dog infection in sheep farms. Vet Parasitol 181: 335-340.

25. Köberl J, Prettenthaler F, Bird DN, 2016. Modelling climate change impacts on tourism demand: a comparative study from Sardinia (Italy) and Cap Bon (Tunisia). Sci Total Environ 543: 1039-1053.

26. SIRED, Sistema Informativo di Raccolta ed Elaborazione Dati, Sardegna Turismo, 2019. Movimento turistico Sardegna per Provincia 2018 su 2017. Available at: http:// osservatorio.sardegnaturismo.it/sites/default/files/2019-03/ OsservatorioTurismo_DatiStagione2018_0.pdf. Accessed January 1, 2020.

27. Risitano AL, Brianti E, Gaglio G, Ferlazzo M, Giannetto S, 2007. Environmental Contamination by Canine Feces in the City of Messina: Parasitological Aspects and Zoonotic Hazards. Proceedings of LXI Congress of the Italian Society for Veterinary Science (SIS Vet), 135-136.

28. Carciofi AC, Takakura FS, de-Oliveira LD, Teshima E, Jeremias JT, Brunetto MA, Prada F, 2008. Effect of six carbohydrate sources in dog diet digestibility and post-prandial glucose and insulin response. J Anim Physiol Anim Nutr (Berl) 92: 326-336.

29. Lewis LD, Magerkurth JH, Roudebush P, Morris ML, Mitchel EE, Teeter SM, 1994. Stool characteristics, gastrointestinal transit time and nutrient digestibility in dogs fed different fiber sources. J Nutr 124: 27165-27185.

30. Pipia AP, Varcasia A, Tamponi C, Sanna G, Soda M, Paoletti B, Traversa D, Scala A, 2014. Canine giardiosis in Sardinia island, Italy: prevalence, molecular characterization, and risk factors. $J$ Infect Dev Ctries 8: 655-660.

31. Sloss MW, Kemp RL, Zajac AM, 1994. Fecal examination: dogs and cats. Veterinary Clinical Parasitology, 6th edition. Ames, IA: lowa State University Press, 17-44.

32. Scala A, Garippa G, Pintus D, 2009. Environmental Contamination by Canine Feces in the City of Alghero (SS): Parasitological Aspects and Zoonotic Hazards. Proceedings of LXIII Congress of the Italian Society for Veterinary Science (SISVet.), 180-182.

33. Simonato G, Cassini R, Morelli S, Di Cesare A, La Torre F, Marcer F, Traversa D, Pietrobelli M, di Regalbono AF, 2019. Contamination of Italian parks with canine helminth eggs and health risk perception of the public. Prev Vet Med 172: 104788.

34. Papini R, Campisi E, Faggi E, Pini G, Mancianti F, 2012. Prevalence of Toxocara canis eggs in dog faeces from public places of Florence, Italy. Helminthologia 49: 154-158. 
35. Tarantini S, Leoni A, Nieddu AM, 1980. L'inquinamento ambientale da nematodi del cane nella città di Sassari. Parassitologia 22: 359.

36. Sánchez Thevenet PS, Jensen O, Mellado I, Torrecillas C, Raso S, Flores ME, Minvielle MC, Basualdo JA, 2003. Presence and persistence of intestinal parasites in canine fecal material collected from the environment in the province of Chubut, Argentine Patagonia. Vet Parasitol 117: 263-269.

37. Paquet-Durand I, Hernández J, Dolz G, Zuniga JR, Schnieder T, Epe C, 2007. Prevalence of Toxocara spp., Toxascaris leonina and ancylostomidae in public parks and beaches in different climate zones of Costa Rica. Acta Trop 104: 30-37.

38. Martínez-Barbabosa I, Cárdenas EMG, Sosa EAA, Lastra RDJP, 2008. Parasitic contamination by dog feces collected from the streets of San Cristobal de Las Casas, Chiapas, Mexico. Vet Mex 39: 173-180.

39. Martin UO, Demonte MA, 2008. Urban contamination with zoonotic parasites in the central region of Argentina. MedicinaBuenos Aires 68: 363-366.

40. Mandarino-Pereira A, de Souza FS, Lopes CWG, Pereira MJS, 2010. Prevalence of parasites in soil and dog feces according to diagnostic tests. Vet Parasitol 170: 176-181.

41. Azian MN, Sakhone L, Hakim SL, Yusri MY, Nurulsyamzawaty Y, Zuhaizam AH, Rodi IM, Maslawaty MN, 2008. Detection of helminth infections in dogs and soil contamination in rural and urban areas. Southeast Asian J Trop Med Public Health 39: 205-212.

42. Kohansal MH, Fazaeli A, Nourian A, Haniloo A, Kamali K, 2017. Dogs' gastrointestinal parasites and their association with public health in Iran. $J$ Vet Res 61: 189-195.

43. Totková A, Klobusický M, Holková R, Friedová L, 2006. Current prevalence of toxocariasis and other intestinal parasitoses among dogs in Bratislava. Epidemiol Mikrobiol Imunol 55: 17-22.

44. Papajová I, Pipiková J, Papaj J, Čižmár A, 2014. Parasitic contamination of urban and rural environments in the Slovak Republic: dog's excrements as a source. Helminthologia 51: 273-280.

45. Gürler AT, Bölükbaş CS, Pekmezci GZ, Umur S, Acici M, 2015. Nematode and cestode eggs scattered with cats-dogs feces and significance of public health in Samsun, Turkey. Ankara Univ Vet Fak Derg 62: 23-26.

46. Dado D et al., 2012. Detection of zoonotic intestinal parasites in public parks of Spain. Potential epidemiological role of microsporidia. Zoonoses Public Health 59: 23-28.

47. Stock TM, Vasseur K, Anton C, 2014. Parasites in parks: the zoonotic potential related to socioeconomic factors and types of pets. Cities Environ (CATE) 7: 3.

48. Genchi M, Ferroglio E, Traldi G, Passera S, Mezzano G, Genchi C, 2007. Fecalizzazione ambientale e rischio parassitario nelle città di Milano e Torino. Professione Veterinaria 41: 15-17.

49. Tamponi $C$, Varcasia A, Brianti E, Pipia AP, Frau V, Pinna Parpaglia ML, Sanna G, Garippa G, Otranto D, Scala A, 2014. New insights on metastrongyloid lungworms infecting cats of Sardinia, Italy. Vet Parasitol 203: 222-226.

50. Varcasia A, Brianti E, Tamponi C, Pipia AP, Cabras PA, Mereu M, Dantas-Torres F, Scala A, Otranto D, 2015. Simultaneous infection by four feline lungworm species and implications for the diagnosis. Parasitol Res 114: 317-321.
51. Varcasia A, Tamponi C, Brianti E, Cabras PA, Boi R, Pipia AP, Giannelli A, Otranto D, Scala A, 2015. Angiostrongylus chabaudi Biocca, 1957: a new parasite for domestic cats? Parasit Vectors 7: 588.

52. Duncan KT, Koons NR, Litherland MA, Little SE, Nagamori Y, 2020. Prevalence of intestinal parasites in fecal samples and estimation of parasite contamination from dog parks in central Oklahoma. Vet Parasitol Reg Stud Rep 19: 100362.

53. Nijsse R, Mughini-Gras L, Wagenaar JA, Ploeger HW, 2014. Coprophagy in dogs interferes in the diagnosis of parasitic infections by faecal examination. Vet Parasitol 204: 304-309.

54. Corda A, Tamponi C, Meloni R, Varcasia A, Parpaglia MLP, Gomez-Ochoa P, Scala A, 2019. Ultrasonography for early diagnosis of Toxocara canis infection in puppies. Parasitol Res 118: 873-880.

55. Paradies P, larussi F, Sasanelli M, Capogna A, Lia RP, Zucca D, Greco B, Cantacessi C, Otranto D, 2017. Occurrence of strongyloidiasis in privately owned and sheltered dogs: clinical presentation and treatment outcome. Parasit Vectors 10: 345.

56. latta Ret al., 2019. Occurrence, diagnosis and follow-up of canine strongyloidiosis in naturally infected shelter dogs. Parasitology 146: 246-252.

57. Viney ME, Lok JB, 2007. Strongyloides spp. WormBook 1: 1-15.

58. Rinaldi L, Maurelli MP, Musella V, Veneziano V, Carbone S, Di Sarno A, Paone M, Cringoli G, 2008. Giardia and Cryptosporidium in canine faecal samples contaminating an urban area. Res Vet Sci 84: 413-415.

59. Capelli G, Di Regalbono AF, lorio R, Pietrobelli M, Paoletti B, Giangaspero A, 2006. Giardia species and other intestinal parasites in dogs in north-east and central Italy. Vet Rec 159: 422-424.

60. Dunn JJ, Columbus ST, Aldeen WE, Davis M, Carroll KC, 2002. Trichuris vulpis recovered from a patient with chronic diarrhea and five dogs. J Clin Microbiol 40: 2703-2704.

61. Traversa $D, 2011$. Are we paying too much attention to cardiopulmonary nematodes and neglecting old-fashioned worms like Trichuris vulpis? Parasit Vectors 4: 32

62. Márquez-Navarro A, García-Bracamontes G, Álvarez-Fernández BE, Ávila-Caballero LP, Santos-Aranda I, Díaz-Chiguer DL, Sánchez-Manzano RM, Rodríguez-Bataz E, Nogueda-Torres B, 2012. Trichuris vulpis (Froelich, 1789) infection in a child: a case report. Korean J Parasitol 50: 69-71.

63. Lalošević D, Lalošević V, Klem I, Stanojev-Jovanović D, Pozio E, 2008. Pulmonary capillariasis miming bronchial carcinoma. Am J Trop Med Hyg 78: 14-16.

64. Government of Sardinia, Italy, 2019. Available at: http:// osservatorio.sardegnaturismo.it. Accessed January 1, 2020.

65. Otranto D, Varcasia A, Solinas C, Scala A, Brianti E, Dantas-Torres F, Annoscia G, Martin C, Mutafchiev Y, Bain O, 2013. Redescription of Cercopithifilaria bainae Almeida Vicente, 1984 (Spirurida, Onchocercidae) from a dog in Sardinia, Italy. Parasit Vectors 6: 132.

66. Varcasia $A$ et al., 2018. Species delimitation based on mtDNA genes suggests the occurrence of new species of Mesocestoides in the Mediterranean region. Parasit Vectors 11: 619.

67. Carta S et al., 2020. Species diversity and molecular insights into phlebotomine sand flies in Sardinia (Italy)- an endemic region for leishmaniasis. Parasitol Res 119: 63-73.

68. Maia C, Cardoso L, 2015. Spread of Leishmania infantum in Europe with dog travelling. Vet Parasitol 213: 2-11. 